\title{
Analysis of Extension Strategies for Improving Adaptive Teaching Ability of College Teachers
}

\author{
https://doi.org/10.3991/ijet.v15i15.15927 \\ Mengqing Han, Nan Zhou $\left({ }^{凶}\right)$, Zhenmin Qiao \\ Shijiazhuang University of Applied Technology, Shijiazhuang, China \\ rocket 2010@sina.com
}

\begin{abstract}
In the new era, college teachers should improve their teaching ability, especially in terms of adaptability. However, most college teachers lack sufficient adaptive teaching ability, failing to create an adaptive teaching environment. To solve the problem, this paper explores deep into the extension strategies for improving the adaptive teaching ability of college teachers. First, the problems of college teachers in adaptive teaching were identified, and the key aspects of adaptive teaching ability were enumerated theoretically. On this basis, several extension strategies were put forward to improve the adaptive teaching ability of college teachers. To evaluate the improving effect, the authors developed an evaluation model for the adaptive teaching ability of college teachers based on the extension theory. Overall, this paper fully explores the improvement of adaptive teaching ability of college teachers via theoretical analysis and modelling. The research results boast good application prospects.
\end{abstract}

Keywords-Teaching ability, college teachers, adaptability, extension strategy, extension evaluation model.

\section{Introduction}

Higher education is the most important way to train senior talents for the country, greatly promoting the development of various fields in the society. It has always been highly valued by the country and government. Especially since the 21 st century, senior talents, as the most important driving force of social development, have been also increasingly valued by the international community. Thus, the development and implementation of higher education has become a research hotspot in modern society [14]. With the continuous progress of modern society and the science and technology, the development model of higher education has been constantly changing from the traditional test-oriented education to the quality-oriented education, and from the traditional classroom teaching method to the method with a comprehensive use of various smart technologies. This has brought higher education to a stage of rapid development [5-8]. In response to the demands for the rapid development of modern higher education, college teachers are required to have strong adaptive teaching abilities. As the main body of higher education, college teachers play a more prominent role. It has become the key to the field of higher education on how to improve the 
teaching abilities of college teachers and teaching quality, especially their adaptive teaching ability according to the continuous changes in the needs for higher education with social development. For this, some scholars have conducted related research, and formed useful research results. For instance, Janssen et al. [9] discussed how to cultivate critical thinking and teaching attitudes of higher education teachers. Pi [10] probed into the ways to improve the teaching ability of college physical education teachers using the MOOC. Vong and Kaewurai [11] discussed how to cultivate the teaching model of critical thinking ability. Yeom et al. [12] explored a new type of teaching concept, guiding nursing staffs to integrate organizational mission, personal beliefs, and educational theories into teaching practice, which provides effective support for adaptive teaching. From the above, the current research mainly focuses on how to improve the teaching ability or teaching quality of college teachers, but it is not deep enough to promote the adaptive teaching ability of college teachers. Especially for disciplines or majors such as the cultural industry that require comprehensive professional knowledge in multiple fields, the teacher's adaptive teaching ability is even more important [13]. On this basis, this paper combines related research results to discuss the improvement of college teachers' adaptive teaching ability, and conducts corresponding extension strategy analysis and evaluation.

This paper consists of 6 parts. The first part gives an overview of the research on the adaptive teaching ability of college teachers; the second part analyzes the problems of college teachers in the adaptive teaching process; the third part enumerates the key aspects of adaptive teaching ability performance of college teachers; the fourth part discusses about the extension strategy of improving college teachers' adaptive teaching ability; the fifth part establishes an evaluation model for the adaptive teaching ability of college teachers based on the extension theory; the sixth part gives the conclusions.

\section{The Current Problems of College Teachers in Adaptive Teaching}

\subsection{Low construction level of teaching staffs}

At present, colleges teachers generally have a low comprehensive professional ability in adaptive teaching, and a talent team of teachers has not been constructed. Many teachers often only focus on professional details and cannot effectively integrate the teaching resources, especially for emerging disciplines or majors in colleges such as the cultural industry that has developed well in recent years. Under the support of policies and technological innovation, senior talents in the cultural industry have more training demands. However, during the implementation process of senior talents training in the cultural industry, it is often impossible to combine the demand orientation of the cultural industry for construction of the teaching staff, resulting in a low level of teachers, and failing to meet the development needs of higher education. 


\subsection{Limited application of intelligent technology}

The modern intelligent technology hasn't been sufficiently applied. Teachers have limited knowledge and weak awareness about the application of modern intelligent technology in higher education. Especially for some elder teachers, due to the lack of intelligent technology, and their reluctancy to spend time on related technology learning or training, some teachers cannot effectively use modern teaching equipment for teaching, and they fail to flexibly apply modern intelligent technology. Moreover, science and technology teachers and liberal arts teachers vary in the application of intelligent technology. For example, compared with the teachers in Control Engineering, Computer Engineering, and other related disciplines, teachers in cultural industry-related field are weaker in the intelligent technology, because of rare contact with it in their teaching and scientific research.

\subsection{Lack of innovation in curriculum teaching}

Curriculum teaching innovation is a key aspect of college teachers' adaptive teaching, reflecting the sustainable development ability of adaptive teaching. At present, the lack of innovation in college curriculum teaching is mainly manifested in three aspects: first, college teachers have a weak awareness of adaptive teaching innovation, and many teachers often only focus on the teaching content in the course, but ignoring the correlation between the teaching contents; second, they lack knowledge reserves and experience of adaptive teaching, e.g., in the curriculum setting and teaching process of the cultural industry, due to the development of the curriculum ideological and political teaching model, college teachers are required to consider not only cultural construction factors, economic construction factors, etc., but also social factors and political factors of the cultural industry; otherwise, it will affect the teaching effect of the curriculum; third, the theory and practice of college teachers' curriculum teaching are disconnected; the theory needs to be verified by practice, while the theory must be higher than practice; the two need to be effectively integrated to benefit the teaching innovation of the curriculum.

\subsection{The insufficient systematicness of curriculum system construction}

At present, the courses of various disciplines or majors offered by colleges are generally set up based on the professional development program or syllabus. But the curriculum program of disciplines and majors is reviewed or changed after five years, ten years or even longer, so it often has a certain lag, and cannot be modified in a timely manner with the social development or changes in needs. This results in no changes and updates of many courses for many years, and the disconnection between curriculum system construction and social development demands are disconnected, failing to meet the dynamics and times requirements of the higher education development. In particular, the disciplines such as the cultural industry which are closely related to social and cultural construction and economic construction, should pay more attention to the construction of the curriculum system. 


\subsection{Unclear positioning of teaching objectives}

The teaching objectives should be positioned to be in line with the development goals of higher education. During the implementation of higher education, the primary task is to clearly define the type and level of professional personnel to be cultivated, and development measures and means to be adopted for achieving the development goals of higher education. Although the goal of current higher education is to pursue quality education, it is still more limited to test-oriented education in the specific teaching implementation process, and lacks the comprehensive quality training of senior talents, which leads to certain differences between the teaching objectives and development goals of higher education. The unclear positioning of teaching goals will result in the failure to formulate effective college student training strategies and talent training approaches during the implementation of higher education, thus causing such problems as weak ability of engineering college students to independently conduct engineering design, and low logic analysis ability of science students, and weak social service ability of college students majoring in economics and cultural industries.

\subsection{Lack of competitiveness in sustainable development}

The problems of higher education in adaptive teaching make it difficult for the cultivation of senior talents to meet the corresponding needs of social employment, that is, the trained senior talents not only have insufficient professional knowledge reserves in the field, but also are often weak in related disciplines or professional knowledge so that many college graduates fail to obtain in-depth research results in the research process after participating in social work, and the competitiveness of sustainable development is not very strong. Therefore, in the implementation process of higher education, college students need to involve themselves in the related industries such as engineering, management, or cultural industry etc. in order to strengthen the competitiveness of college students in social sustainable development.

\section{The Key Aspects of Adaptive Teaching Ability to be Improved for College Teachers}

In this study, it's believed that during the implementation of modern higher education, the college teachers' adaptive teaching ability needs to be reflected in many aspects such as educational concepts, educational models, teaching means, teaching methods, teaching evaluation and teaching content.

\subsection{Educational concepts}

As the main body of higher education, college teachers are not only the executors of higher education talent training programs, but also the implementers of modern higher education concepts. To train high-level talents suitable for the development 
needs of modern society, the first is to ensure that college teachers have a modern concept of higher education, and can adjust the concept according to the changes in the goal of higher education and the development of modern social science and technology. Then, the strategies of higher education can be adjusted and planned accordingly in terms of educational mission, educational goals, educational principles, educational requirements, and educational objectives.

\subsection{Educational model}

Generally, the educational model is compatible with the country's economic and political models. When the socio-economic level develops to a new stage, the higher education model for the training of senior talents should also be adjusted accordingly, to meet the adaptive requirements of social development. In the past, higher education mostly focused on indoctrination education and test-oriented education. It was mechanized from the aspects of subject planning, professional curriculum setting, talent training goal setting, professional course content teaching, and teaching achievement evaluation, and lacked effective communication and adjustment. To this end, with the continuous progress of society, the implementation of higher education requires college teachers to have a good adaptability to the educational model, and gradually transform the traditional indoctrination education and test-oriented education into enlightenment education and quality education, which facilitates the training of senior professionals.

\subsection{Teaching means}

Following the continuous development and innovation of science and technology, teaching means in higher education have been constantly changing and innovating. Especially the constant emergence and in-depth development of various modern artificial intelligence technologies make the teaching means more abundant and diverse. Therefore, with the application of computer technology, network technology, information technology, virtual reality technology, big data technology, etc. deeply continuously in the application of higher education, the good ability to apply good teaching means can be conducive to the efficient and convenient transfer of professional knowledge, as well as the effective improvement of teaching quality and teaching efficiency.

\subsection{Teaching methods}

The teaching method contains two aspects: the teaching method of college teachers and the learning method of college students. The adaptability to the teaching method requires an effective unity between the knowledge transference of college teachers and the knowledge learning of college students. Due to changes in the development background of higher education, educational concepts and educational models are also adjusted accordingly, and various new teaching types need to be matched with corresponding teaching methods, to effectively promote the teaching quality in higher 
education. The teaching methods need to be properly implemented in the planning of teaching guidelines, the formulation of basic teaching methods, the implementation of specific teaching methods and the execution of teaching methods. Meanwhile, considering that college teachers are the main body of teaching, it is necessary to ensure the dominance of the teachers' teaching methods in the process, while flexibly adopting targeted teaching strategies based on different learning methods of students.

\subsection{Teaching evaluation}

At present, there are many forms of teaching evaluation in higher education. From the perspective of evaluation subjects, it includes expert evaluations, supervisor evaluation, teacher mutual evaluation, and students' evaluation of teaching etc.; from the perspective of evaluation content, it includes discipline construction evaluation, professional construction evaluation, subject system construction evaluation, classroom teaching evaluation and after-class comprehensive evaluation; from the perspective of evaluation methods, it includes online evaluation, offline evaluation, on-site evaluation, anonymous evaluation, etc. From a functional point of view, these evaluation forms have a certain role in promoting the implementation of college teaching. However, due to their differences in evaluation content or emphasis, different teaching evaluation forms often have corresponding application scope. Especially as modern intelligent technology is applied deeper in higher education, the teaching evaluation must consider the dynamics of higher education development.

\subsection{Teaching content}

Generally, no matter it is science major or liberal arts major, the course teaching in higher education mainly includes three aspects: basic curriculum teaching, professional curriculum teaching and expansive curriculum teaching. Basic curriculum teaching mainly imparts basic and principled subject knowledge within a subject or major, which is the basic knowledge reserve process for professional learning; the teaching of professional curriculum is mainly to impart higher-level professional knowledge, as a process of cultivating professional talents who have the ability to solve scientific research problems independently; compared with the basic curriculum teaching, it's more subdivided and deeper in the professional level; Expansive curriculum teaching generally imparts multi-field and cross-disciplinary professional knowledge. It has a good supporting role for basic curriculum teaching and professional curriculum teaching, positively promoting students' learning horizons and knowledge categories. The adaptability to the teaching content means requiring the college teachers to reasonably select, design, and teach the teaching content in accordance with the teaching levels of different curriculum in the process of teaching professional knowledge, and to adjust teaching content in time based on the changes in teaching objectives, teaching plans or teaching tasks, etc. 


\section{Analysis of Extension Strategies for Improving the Adaptive Teaching Ability of College Teachers}

As above, the authors summarized the key aspects of adaptive teaching ability for college teachers. On this basis, the extension theory was applied to analyze the extension strategies for enhancing the adaptive teaching ability of college students from the aspects below:

\subsection{Strengthening of the adaptive teaching concept}

First, encourage college teachers to actively learn about advanced teaching concepts, understand the current development of higher education, and actively combine goals, strategies, programs, policies, and objectives of higher education, etc. to reasonably formulate corresponding syllabus, teaching plan, teaching plan and teaching strategy on the basis of discipline development and professional planning; secondly, strengthen the familiarity and mastery of the relevant teaching methods, teaching means, teaching approaches, etc. under the support of modern intelligent technology, so that college teachers continue to innovate teaching methods, improve teaching means, and form a rich variety of teaching forms, which can provide good help and support for the subsequent curriculum teaching.

\subsection{Improvement in the professional quality}

Judging from the teaching effect of newly launched professional courses in colleges, an important factor affecting the adaptive teaching ability of college teachers is that the comprehensive qualities of professional teachers are weak, and their knowledge reserves and professional qualities cannot meet the requirements of adaptive teaching. Taking the teaching of cultural industry major as an example, its knowledge category also involves economic construction, political construction, customs, sociology, and international development trends etc. in addition to cultural construction; If the teachers have insufficient experience and weak knowledge reserves, they shall feel it difficult to form a systematic and in-depth discussion on the development of the cultural industry. For this, it's important to strengthen the assessment of the professional abilities among college teachers and improving their comprehensive professional quality.

\subsection{Construction of excellent course system}

The transfer of professional knowledge generally needs to be carried out according to the corresponding course materials. In particular, the highly professional course teaching requires more support of course materials, because the teaching of professional courses is highly hierarchic and phased, and the gradual imparting process of professional knowledge often needs supports of corresponding course system in this process. However, due to the diversification of teaching content, and the unevenness 
of the course materials quality, the curriculum system does not have systematic and sustainable development capabilities, making it difficult to meet the needs of adaptive teaching in colleges. Therefore, it is necessary to strengthen the construction of college subject systems such as the excellent course system with professional characteristics, and then set up an excellent course system that meets the development of disciplines or professions.

\subsection{Organization of adaptive teaching practice activities}

First, organize professional curriculum teaching competition activities, with clear teaching goals as the standard of evaluation, i.e., adopt the adaptive teaching around the knowledge points, difficulties, and key points of professional curriculum teaching gradually, and tap the teaching innovation potential of professional course teachers through the comprehensive use of various forms of intelligent teaching methods; hold a variety of teaching forums such as high-level teacher forums, famous teacher observation courses and famous teachers into classrooms, and provide training for college teachers on teaching skills, teaching methods, teaching concepts and teaching literacy in the professional field. It's necessary not only to enhance the theoretical basis of college teachers' adaptive teaching, but also to improve their practical ability. Also, the colleges should strengthen the disciplinary construction and professional construction certification capabilities through a series of theme activities, optimize the teaching environment and atmosphere of college teachers for adaptive teaching, enhance the sense of belonging and professional values of college teachers for adaptive teaching, and stimulate the development motivation of college teachers for adaptive teaching, as well as the enthusiasm and initiative of teaching work.

\subsection{Familiarity and application of intelligent education platform and technology}

With the rapid development of modern science and technology, various artificial intelligence technologies have begun to be applied widely in higher education. They not only provide a very rich variety of intelligent teaching tools and methods for the implementation of higher education, but also help to establish various forms of intelligent education platforms and teaching research centers for improving the intelligence and adaptability of higher education. Thus, it offers a very effective teaching method for highly practical professional course teaching. Taking the teaching of cultural industry courses as an example, the cultural industry is a professional course with strong practicality. To enhance the ability of cultural industry course teachers to use modern intelligent technology or intelligent platforms for adaptive teaching, the course teachers need to master one or more intelligent education platforms under the premise of excellent professional qualities. At present, flipped classroom, MOOC class, rain classroom, and cloud classroom are the most used ones. For some majors, teachers are often required to provide intuitive visual or sensory feelings for the students, such as dance majors, art majors, etc., and the course teachers should also understand or master certain virtual reality technology, and 3D printing technology, etc. 
For some engineering courses, sometimes teachers are required to have certain computer technology, network technology, control technology and information technology, because the understanding, familiarity and mastery of these intelligent education platforms and technologies will be more helpful to the improvement of college teachers' adaptive teaching ability.

\subsection{Industry-university-research integration}

Curriculum teaching in higher education generally includes three forms: classroom teaching, experimental teaching, and practical teaching. Despite different emphasis of these three forms, they are basically carried out around the theoretical knowledge and practical knowledge of the curriculum, and there is still a great distance from the real engineering practice and enterprise production practice. Under such teaching model, the college students cultivated often do not have strong independent scientific research capabilities and social practice ability, resulting in a poor connection with social industry development. Therefore, in order to improve the theoretical innovation and scientific research practice of college students, it is necessary to enhance the adaptability of college teachers in curriculum teaching, and necessary to integrate industrial knowledge and scientific research projects into the traditional classroom teaching, experimental teaching and practical teaching, thereby forming a set of advanced industry-university-research model of teaching courses. To this end, college teachers are encouraged to strengthen industry, scientific research projects and academic cooperation in the course of course teaching, and combine the needs of personnel training to actively promote the teaching mode of social enterprises entering classrooms and scientific research projects entering classrooms. At the same time, using the industrial platform of social enterprises and the research platform of scientific research projects, establish an industry-university-research cooperation mechanism and development model for the cultivation of senior talents, and form an industryuniversity-research cooperation platform with special characteristics of higher education.

\section{An Evaluation Model for the Adaptive Teaching Ability of College Teachers Based on the Extension Theory}

The extension strategies discussed above play an important role in improving college teachers' adaptive teaching ability. However, due to the different strategies implemented by different universities and the acceptance of different curriculum teachers, the adaptive teaching abilities of different educational objects also vary. In order to improve the adaptive teaching abilities of college teachers in a targeted manner, it is necessary to effectively evaluate their adaptive teaching abilities. To this end, based on extension theory [14-17], this paper proposes an evaluation model of college teachers' adaptive teaching ability. 


\subsection{Extension evaluation index}

By comprehensively analyzing the key aspects and related influencing factors of college teachers' adaptive teaching ability, the authors chose college teachers' teaching content selection ability $\mathrm{c} 1$, adjustment ability of teaching means and teaching methods c2, teaching research and reform ability c3, integration ability of teaching theory and practice $c 4$, intelligent technology application ability c5, and teaching interaction and feedback ability c6 etc. as evaluation indicators for college teachers' adaptive teaching ability. Teaching content selection ability reflects the adaptability of college teachers to teaching design; adjustment ability of teaching methods and teaching method reflects the adaptability to teaching integration; teaching research and reform ability reflects the adaptability to teaching innovation; integration ability of teaching theory and practice reflects the adaptability to teaching practice, the ability of intelligent technology application reflects the adaptability to teaching development, and the ability of teaching interaction and feedback reflects the adaptability to teaching exchange. From this, the extension evaluation index set $\mathrm{C}$ for the adaptive teaching ability of college teachers was established:

$$
\boldsymbol{C}=\left\{c_{1}, c_{2}, c_{3}, c_{4}, c_{5}, c_{6}\right\}
$$

\subsection{The classical domain and node domain of extension evaluation}

Different evaluation indicators often have different value ranges, and thus the corresponding classical domains also vary. To ensure generality of the expression, it's assumed that there are $\mathrm{m}$ extension evaluation indicators for college teachers 'adaptive teaching ability, the $\mathrm{i}$-th evaluation index is divided into $\mathrm{n}$ extension evaluation levels, and the classical domain of the $\mathrm{i}$-th evaluation index at the $\mathrm{j}$-th evaluation level is $V_{i j}=\left[v_{i j}^{a}, v_{i j}^{b}\right]$, then the matter-element model $\mathrm{Rj}$ of the $\mathrm{j}$-th classical domain is expressed as:

$$
\boldsymbol{R}_{j}=\left(N_{j}, C, V\right)=\left[\begin{array}{ccc}
N_{j} & c_{1} & V_{1 j} \\
& \vdots & \vdots \\
& c_{i} & V_{i j} \\
& \vdots & \vdots \\
& c_{m} & V_{m j}
\end{array}\right]=\left[\begin{array}{ccc}
N_{j} & c_{1} & {\left[v_{1 j}^{a}, v_{1 j}^{b}\right]} \\
& \vdots & \vdots \\
& c_{i} & {\left[v_{i j}^{a}, v_{i j}^{b}\right.} \\
& \vdots & \vdots \\
& c_{m} & {\left[v_{m j}^{a}, v_{m j}^{b}\right.}
\end{array}\right]
$$

where, $\mathrm{Nj}$ is the name of the classical domain matter-element, $\mathrm{C}$ is the characteristic of the classical domain matter-element, and $\mathrm{V}$ is the characteristic value.

Then, the corresponding node domain matter-element model is 


$$
\boldsymbol{R}_{o}=\left(N_{o}, C, V_{o}\right)=\left[\begin{array}{ccc}
N_{o} & c_{1} & V_{1 o} \\
& \vdots & \vdots \\
& c_{i} & V_{i o} \\
\vdots & \vdots \\
& c_{m} & V_{m o}
\end{array}\right]=\left[\begin{array}{ccc}
N_{o} & c_{1} & {\left[\min _{1 \leq j \leq n}\left(v_{1 j}^{a}\right), \max _{1 \leq j \leq n}\left(v_{1 j}^{b}\right)\right]} \\
\vdots & \vdots \\
& c_{i} & {\left[\min _{1 \leq j \leq n}\left(v_{i j}^{a}\right), \max _{1 \leq j \leq n}\left(v_{i j}^{b}\right)\right]} \\
\vdots & \vdots \\
& c_{m} & {\left[\min _{1 \leq j \leq n}\left(v_{m j}^{a}\right), \max _{1 \leq j \leq n}\left(v_{m j}^{b}\right)\right]}
\end{array}\right]
$$

where, No is the name of the node domain matter-element, and Vo is its characteristic value.

\subsection{Weights of extension evaluation indicators}

Different extension evaluation indicators may have different effects on the evaluation results, so the weights of evaluation indicators will also vary. Due to its calculation simplicity, reliability, and rationality [18-21], the AHP method was used to obtain the weight of extension evaluation index. Through expert survey, the scale of 1-9 was adopted to score the importance of the indicators, and then obtain the initial evaluation matrix B:

$$
\boldsymbol{B}=\left[\begin{array}{ccccc}
b_{11} & \cdots & b_{1 i} & \cdots & b_{1 m} \\
\cdots & \vdots & \cdots & \vdots & \cdots \\
b_{i 1} & \cdots & b_{i i} & \cdots & b_{i m} \\
\cdots & \vdots & \cdots & \vdots & \cdots \\
b_{m 1} & \cdots & b_{m i} & \cdots & b_{m m}
\end{array}\right]
$$

Equation (4), bij is the initial score value of the extension evaluation index, and satisfies $1 \leq b_{i j}=\frac{1}{p_{j i}} \leq 9 \quad, b_{i i}=1,1 \leq i, j \leq b$.

The consistency index $\mathrm{CI}$ and consistency ratio $\mathrm{CR}$ are calculated as:

$$
\begin{aligned}
& C I=\frac{\lambda(\boldsymbol{B})-n}{n-1} \\
& C R=C I / R I
\end{aligned}
$$

where, $\lambda(B)$ is the maximum eigenvalue of the initial evaluation matrix $B$, and $R I$ is a random consistency index, which can be obtained by look-up table

If satisfying $C R<0.1$, then the weight wi of the i-th evaluation indicator was obtained, namely 


$$
w_{i}=\sum_{j=1}^{m} b_{i j} / \sum_{i=1}^{m} \sum_{j=1}^{m} b_{i j}
$$

\subsection{Implementation of extension evaluation model}

If there is an extension evaluation object $\mathrm{P}$, its matter-element model RP is:

$$
\boldsymbol{R}_{P}=\left(N_{P}, C, V_{P}\right)=\left[\begin{array}{ccc}
N_{P} & c_{1} & V_{1 P} \\
& \vdots & \vdots \\
& c_{i} & V_{i P} \\
\vdots & \vdots \\
& c_{m} & V_{m P}
\end{array}\right]
$$

where, NP is the name of RP, and VP is the characteristic value of RP.

Then, the extension distance $\mathrm{\rho}(\mathrm{Rj})$ between the extension evaluation object $\mathrm{P}$ and the $\mathrm{j}$-th classical domain matter-element $\mathrm{Rj}$ about the $\mathrm{i}$-th evaluation index is expressed as:

$$
\rho_{i}\left(\boldsymbol{R}_{j}\right)=\left|V_{i P}-\frac{v_{i j}^{a}+v_{i j}^{b}}{2}\right|-\frac{v_{i j}^{b}-v_{i j}^{a}}{2}
$$

The extension distance $\rho$ i(Ro) between the extension evaluation object $\mathrm{P}$ and the node domain matter-element Ro about the i-th evaluation index is expressed as:

$$
\rho_{i}\left(\boldsymbol{R}_{o}\right)=\left|V_{i P}-\frac{v_{i o}^{a}+v_{i o}^{b}}{2}\right|-\frac{v_{i o}^{b}-v_{i o}^{a}}{2}
$$

The extension correlation function $\mathrm{Ki}(\mathrm{Rj})$ between the extension evaluation object $\mathrm{P}$ and the $\mathrm{j}$-th classical domain matter-element $\mathrm{Rj}$ about the $\mathrm{i}$-th evaluation index is expressed as:

$$
K_{i}\left(\boldsymbol{R}_{j}\right)= \begin{cases}-\rho_{i}\left(\boldsymbol{R}_{j}\right) /\left|V_{i j}\right| & V_{i P} \in V_{i j} \\ \rho_{i}\left(\boldsymbol{R}_{j}\right) /\left(\rho_{i}\left(\boldsymbol{R}_{o}\right)-\rho_{i}\left(\boldsymbol{R}_{j}\right)\right) & V_{i P} \notin V_{i j}\end{cases}
$$

The weighted extension correlation $\tau(\mathrm{Rj})$ between the extension evaluation object $\mathrm{P}$ and the $\mathrm{j}$-th classical domain matter-element $\mathrm{Rj}$ about all extension evaluation indicators is expressed as:

$$
\tau\left(\boldsymbol{R}_{j}\right)=\sum_{i=1}^{m}\left(w_{i} * K_{i}\left(\boldsymbol{R}_{j}\right)\right)
$$


Therefore, the classical domain of the extension evaluation object $\mathrm{P}$ was obtained according to the weighted extension correlation $\tau(\mathrm{Rj})$, that is, determine the adaptive teaching ability evaluation level of the college teachers for the extension evaluation object $\mathrm{P}$.

\section{Conclusion}

The main conclusions of this study are as follows:

1. This study analyzed the current development situation of college teachers' adaptive teaching, and pointed out the existing problems of the college teachers in adaptive teaching from the aspects of the construction of teaching staffs, the application of intelligent technology, the innovation of curriculum teaching, the construction of curriculum system, the positioning of teaching objectives and the competitiveness of sustainable development.

2. It also discusses about the key aspects of college teachers' adaptive teaching ability, which should be improved in terms of educational concepts, educational models, teaching means, teaching methods, teaching evaluation, and teaching content respectively. Meanwhile, the extension strategies were also proposed to improve the adaptive teaching ability of college students.

3. Through the combination of AHP and extension theory, an evaluation model of college teachers' adaptive teaching ability was established, including the specific implementation process, which provides good supports for quantitative analysis of college teachers' adaptive teaching ability.

\section{$7 \quad$ Acknowledgement}

This research was supported by Shijiazhuang confederation of Social Sciences (No. 2019zjpy24).

\section{$8 \quad$ References}

[1] Thies, K., Kordts-Freudinger, R. (2019). German higher education academic staff's positive emotions through work domains. International Journal of Educational Research, 98: 112. https://doi.org/10.1016/j.ijer.2019.08.004

[2] Hensley, N. (2018). Transforming higher education through trickster-style teaching. Journal of Cleaner Production, 194: 607-612. https://doi.org/10.1016/j.jclepro.2018.05.116

[3] Rubio-Alcalá, F.D., Arco-Tirado, J.L., Fernández-Martín, F.D., López-Lechuga, R., Barrios, E., Pavón-Vázquez, V. (2019). A systematic review on evidences supporting quality indicators of bilingual, plurilingual and multilingual programs in higher education. Educational Research Review, 27: 191-204. https://doi.org/10.1016/j.edurev.2019.03.003

[4] Jay, S., Jones, H. (2019). Towards a framework for higher education for marine spatial planning. Marine Policy, 99: 230-238. https://doi.org/10.1016/j.marpol.2018.10.039 
[5] Ahmad, M.F., Ghapar, W.R.G.W. A. (2019). The era of artificial intelligence in Malaysian higher education: impact and challenges in tangible mixed-reality learning system toward self-exploration education (SEE). Procedia Computer Science, 163: 2-10. https://doi.org/ 10.1016/j.procs.2019.12.079

[6] Brooks, R. (2018). Higher education mobilities: a cross-national European comparison. Geoforum, 93: 87-96. https://doi.org/10.1016/j.geoforum.2018.05.009

[7] Bezanilla, M.J., Fernández-Nogueira, D., Poblete, M., Galindo-Domínguez, H. (2019). Methodologies for teaching-learning critical thinking in higher education: The teacher's view. Thinking Skills and Creativity, 33: 100584. https://doi.org/10.1016/j.tsc.2019.1005 $\underline{84}$

[8] Aldowah, H., Al-Samarraie, H., Fauzy, W.M. (2019). Educational data mining and learning analytics for 21 st century higher education: A review and synthesis. Telematics and Informatics, 37: 13-49. https://doi.org/10.1016/j.tele.2019.01.007

[9] Janssen, E.M., Mainhard, T., Buisman, R.S., Verkoeijen, P.P., Heijltjes, A.E., van Peppen, L.M., van Gog, T. (2019). Training higher education teachers' critical thinking and attitudes towards teaching it. Contemporary Educational Psychology, 58: 310-322. https://doi. org/10.1016/j.cedpsych.2019.03.007

[10] Pi, Z. (2018). Study on the application of MOOC in the teaching practice of College Physical Education Course. In 2017 5th International Education, Economics, Social Science, Arts, Sports and Management Engineering Conference (IEESASM 2017), pp. 20-23. https ://doi.org/10.2991/ieesasm-17.2018.5

[11] Vong, S.A., Kaewurai, W. (2017). Instructional model development to enhance critical thinking and critical thinking teaching ability of trainee students at regional teaching training center in Takeo province, Cambodia. Kasetsart Journal of Social Sciences, 38(1): 8895. http://doi.org/10.1016/j.kjss.2016.05.002

[12] Yeom, Y., Miller, M.A., Delp, R. (2018). Constructing a teaching philosophy: Aligning beliefs, theories, and practice. Teaching and Learning in Nursing, 13(3): 131-134. https:// doi.org/10.1016/j.teln.2018.01.004

[13] Cheng, J. (2018). Innovation of practical teaching system of cultural industry management specialty in universities -under the background of integration of internet and culture industry, 34(6): 104-107.

[14] Chen, R.M., Yang, S.C., Wang, C.M. (2017). MRI brain tissue classification using unsupervised optimized extenics-based methods. Computers \& Electrical Engineering, 58: 489501. http://doi.org/10.1016/j.compeleceng.2017.01.018

[15] Zhang, X., Yue, J. (2017). Measurement model and its application of enterprise innovation capability based on matter element extension theory. Procedia engineering, 174: 275-280. https://doi.org/10.1016/j.proeng.2017.01.136

[16] Ren, J. (2018). Technology selection for ballast water treatment by multi-stakeholders: a multi-attribute decision analysis approach based on the combined weights and extension theory. Chemosphere, 191: 747-760. https://doi.org/10.1016/j.chemosphere.2017.10.053

[17] Seyedmohammadi, J., Sarmadian, F., Jafarzadeh, A.A., McDowell, R.W. (2019). Development of a model using matter element, AHP and GIS techniques to assess the suitability of land for agriculture. Geoderma, 352: 80-95. https://doi.org/10.1016/j.geoderma.2019.05. $\underline{046}$

[18] Solangi, Y.A., Tan, Q., Mirjat, N.H., Ali, S. (2019). Evaluating the strategies for sustainable energy planning in Pakistan: An integrated SWOT-AHP and Fuzzy-TOPSIS approach. Journal of Cleaner Production, 236: 117655. https://doi.org/10.1016/j.jclepro.2019.117655 
[19] Carra, S., Monica, L., Vignali, G. (2019). Reduction of workers' hand-arm vibration exposure through optimal machine design: AHP methodology applied to a case study. Safety Science, 120: 706-727. https://doi.org/10.1016/j.ssci.2019.07.034

[20] Kokangül, A., Polat, U., Dağsuyu, C. (2017). A new approximation for risk assessment using the AHP and Fine Kinney methodologies. Safety Science, 91: 24-32. http://doi.org/10. 1016/j.ssci.2016.07.015

[21] Nagata, K., Nakamura, T., Farouk, A. (2017). Quantum cryptography based on the Deutsch-Jozsa algorithm. International Journal of Theoretical Physics, 56: 2887-2897. https://doi.org/10.1007/s10773-017-3456-x

\section{Authors}

Han Mengqing, graduated from North China University of Science and Technology with a master's degree in English interpretation in 2015. She is now working at Shijiazhuang University of Applied Technology. The main research direction is English teaching, English translation, English literature and intercultural communication. Email: mmengdream@126.com

Nan Zhou, graduated from the Kharkiv National University of Ukraine with a doctorate degree in education in 2016. He is now working at Shijiazhuang University of Applied Technology. The main research directions are pedagogy, philosophy, educational psychology. Email: rocket2010@sina.com

Zhenmin Qiao, graduated from Hebei Normal University with a master degree in computer science and engineering in 2001. He is currently an associate professor at Shijiazhuang University of Applied Technology. The main research directions are computer science, pedagogy. Email: qiaozm666@163.com

Article submitted 2020-06-01. Resubmitted 2020-07-03. Final acceptance 2020-07-04. Final version published as submitted by the authors. 